Doi: $10.32481 /$ djph.2021.09.003

\title{
The State of Dementia in Delaware:
}

\section{History and Efforts to Ensure Availability of Necessary Supports and Services}

\author{
Julie P. Devlin, Esq. ${ }^{1}$ and Sydney Garlick, MPH, $\mathrm{MSW}^{2}$
}

1. Senior Planner and Legal Services Developer, Division of Services for Aging and Adults with Physical Disabilities, Department of Health and Social Services, State of Delaware

2. Former Behavioral Health Coordinator, Office of the Lieutenant Governor, State of Delaware

\section{Introduction}

The impact of Alzheimer's disease and related dementias (ADRD) is far-reaching. It is estimated that over six million Americans currently have Alzheimer's disease. The annual number of Alzheimer's cases and other dementias is projected to triple by 2050 . While many cases of earlyonset Alzheimer's disease exist in those under the age of age 65 - there are approximately 200,000 cases of persons under age 65 with the disease today - the majority of persons with the disease are aged 65 and over. By 2050, the number of people age 65 and older with Alzheimer's disease is projected to reach 12.7 million. One in three seniors dies with Alzheimer's or another dementia. In 2019, over 121,000 Americans died of Alzheimer's disease, making it the country's sixth leading cause of death and the fifth-leading cause of death for those age 65 and older. ${ }^{1}$

In Delaware, the prevalence of the disease is equally daunting. It is estimated that there are currently 19,000 Delawareans aged 65 and older living with Alzheimer's disease. This figure represents $11 \%$ of the State's senior population. As would be expected, the number of people with Alzheimer's disease in Delaware has grown since the State, like the rest of the country, is in the midst of an unprecedented growth in the older population. Between 2020 and 2025, the number of persons aged 65 and over with Alzheimer's disease in Delaware is expected to grow by over $21 \%$ (to 23,000 people). ${ }^{1}$

The economic impact of ADRD has been well documented. Family members and friends provided nearly $\$ 257$ billion in unpaid care to people living with Alzheimer's and other dementias in $2020 .^{2}$ In addition, numerous studies point to the significant impact on the lives of individuals who serve as informal caregivers. The American Psychological Association in summarizing these findings states that, "While caregiving can be rewarding and positive, many family caregivers experience significant physical, psychological, and financial stressors in association with their caregiving role."

To respond to these needs, Delaware has made significant strides in developing the dementiacapability of its long-term services and supports (LTSS) system. Delaware's small size has been an advantage in the development of a dementia-capable system in that organizations work together to share resources, cultivate a trained workforce, and promote advancements in the responsiveness of the LTSS system.

\section{Federal Response Dementia and State Mandated Plans}

The Administration for Community Living (ACL), an agency of the U.S. Department of Health and Human Services, has spent significant resources to enhance the federal response to dementia. Under the agency's leadership, the National Alzheimer's and Dementia Resource Center 
(NADRC) was formed. The goals of the NADRC include, but are not limited to, the provision of expert technical assistance to ACL and its grantees, as well as making program information and resources available to individuals and organizations outside the Alzheimer's grantee community. ACL also provides grants that collectively seek to achieve the following objectives:

- Create state-wide, person-centered, dementia-capable home and community-based service systems;

- Translate and implement evidence-based supportive services for persons living with ADRD and their caregivers at the community level;

- Work with public and private entities to identify and address the special needs of persons living with ADRD and their caregivers; and

- Offer direct services and supports to persons living with ADRD and their caregivers.

Another way the federal government has ensured that states respond to the ever-growing needs of people living with ADRD and their caregivers is through the state planning process, as mandated in the Older Americans Act (OAA). Congress passed the OAA in 1965 in response to concern by policymakers about a lack of community social services for older persons. The original legislation established authority for grants to states for community planning and social services, research and development projects, and personnel training in the field of aging. ${ }^{3}$

Although older individuals may receive services under many other federal programs, today the OAA is considered to be a major vehicle for a wide array of service programs through a national network of 56 state units on aging, 618 area agencies on aging, nearly 20,000 service providers, 281 Tribal organizations, and one Native Hawaiian organization representing 400 Tribes.

The OAA requires State Units on Aging to develop a State Plan on Aging every two to four years. The State Plan on Aging functions as State Units on Aging's contract with ACL. It allows the State to receive funding under Titles III and VII of the OAA. Titles III and VII provide for funding for important services for older adults, known as "core" programs, such as personal care, respite, legal services, case management and congregate and home-delivered meals. Each year, ACL also requires specific areas to be addressed in the state plan, including services for people living with ADRD and their caregivers.

\section{Delaware's State Plan on Aging}

As a single Planning and Service Area (PSA), the Division of Services for Aging and Adults with Physical Disabilities (DSAAPD), one of eleven divisions of the Delaware Department of Health and Social Services, serves as Delaware's State Unit on Aging (SUA). The agency delivers and contracts for services for older persons at the state and local level. Additionally, DSAAPD is responsible for coordinating services for adults with physical disabilities in Delaware. To carry out these activities, DSAAPD maintains strong partnerships with organizations within the aging and disabilities networks. DSAAPD utilizes its State Plan on Aging to address the growing and changing needs of older Delawareans and persons with disabilities, including those with ADRD.

Through the state plan, DSAAPD provides funding for a variety of programs and services for older Delawareans and their caregivers including supportive services, nutrition programs, disease 
prevention and health promotion initiatives, elder rights protection activities, and caregiver support programs. Delaware's current plan is effective from October 2020 through September $2024^{4}$ and focuses on the following goals:

- Promoting excellence in the delivery of core Older Americans Act Programs;

- Empowering older adults, persons with disabilities and their caregivers to be active, engaged, and supported in their homes and/or communities of choice;

- Increasing the development and implementation of business-related strategies that promote innovation, collaboration, and sustainability of aging and disability network partners;

- Expanding and leveraging alignments with strategic partners to support integration of discretionary grant programs into Older Americans Act core programs;

- Promoting person-centered planning and participant direction in community-based and long-term care service options;

- Promoting access to and efficiencies of home and community-based services which enable participants to direct their own care;

- Preventing abuse, neglect and exploitation while protecting the rights of older Delawareans and persons with disabilities; and

- Supporting and enhancing multi-disciplinary responses to elder abuse, neglect, and exploitation. ${ }^{5}$

Specific to dementia, DSAAPD is leading the effort to become a dementia-friendly state, ensuring that communities throughout Delaware are equipped to support persons living with dementia and their caregivers. This will foster the ability of persons living with dementia to not only age in place but thrive in their communities. ${ }^{6}$

\section{Delaware State Plan to Address Alzheimer's Disease and Related Disorders}

Delaware was one of the first states to implement an Alzheimer's State Plan to address the needs of the growing population. DSAAPD, in conjunction with the Alzheimer's Association Delaware Valley chapter, released the Delaware State Plan to Address Alzheimer's Disease and Related Disorders in 2014. ${ }^{7}$ This plan was developed out of recognition of the enormous social, emotional, and economic impact of Alzheimer's disease and the need to find creative approaches to support the many people impacted in Delaware. The Delaware State Plan to Address Alzheimer's Disease and Related Disorders ${ }^{8}$ laid the groundwork for collaborative efforts to improve the State's response to persons with ADRD and their families.

The Alzheimer's Plan highlights the fact that there are gaps within Delaware's current dementia capable LTSS system. Some of the specific gaps identified include the need for more legal services for persons with ADRD and their caregivers; the need for supportive services/technologies for persons with ADRD who live alone; the need for training and consultation for ADRD caregivers; the need for more services to allow ADRD caregivers to take a break from their caregiving responsibilities; and the need for services that can support ADRD caregivers when emergencies arise. 
The plan identified five goals, each with accompanying objectives and strategies. Broadly speaking, the plan outlines actions to increase awareness of and understanding about Alzheimer's disease; bring focused attention to the development of long-term care services for persons with Alzheimer's disease; strengthen support for caregivers; improve the capacity of Delaware's workforce to respond to the needs of persons with Alzheimer's disease; and increase Delaware's capacity for Alzheimer's disease related research and data collection.

Through a steering committee to implement the Alzheimer's Plan, five workgroups, corresponding with the five goals of the Plan, were developed. This State Plan was ultimately incorporated into the State Plan on Aging to ensure that the goals could be accomplished and sustained once the Alzheimer's Plan, and the working groups associated with it, folded. This truly collaborative effort has included partners from around the state including the American Association of Retired Persons (AARP), Alzheimer's Association, ChristianaCare, Delaware State University, DSAAPD, home health agencies, the University of Delaware, community advocates, and many more.

\section{Delaware's Actions to Address ADRD}

Through the work of the Delaware State Plan to Address Alzheimer's Disease and Related Disorders, partners from across the state have come together to enhance supports and services for people living with dementia and their caregivers. The Plan led to not only creative and innovative new programs, but a federal grant awarded to the State for its efforts.

\section{Sustained Efforts from the Delaware State Plan to Address Alzheimer's Disease and Related Disorders}

Much was achieved with the Alzheimer's Plan, with many of the activities continuing beyond its culmination. The first goals sought to promote public awareness of Alzheimer's disease. Much of the work centered on soliciting nontraditional partners, like the faith-based community, to let people know about the warning signs of ADRD. Evidence based messaging was disseminated throughout the state, including the Alzheimer's Association Facts and Figures Report. A brochure was developed on what steps to take once someone has been diagnosed with ADRD. This brochure was made available at pharmacies and doctor's offices statewide. An Alzheimer's Toolkit, housed on the DSAAPD website, ${ }^{9}$ to promote resources and services was also developed. The brochure and toolkit also helped meet the goal of strengthening supports for caregivers of those living with ADRC. Another goal pursued the improvement of the delivery of services to persons with Alzheimer's disease. Part of these efforts encompassed inclusion of Alzheimer's disease as a focus area in the Health Promotion and Disease Prevention Section of the Division of Public Health (DPH). Since brain health is an important issue on the national level, ${ }^{10}$ it is also something DPH is now focused on.

Through the Alzheimer's Plan, Delaware worked to achieve an Alzheimer's-competent workforce. Partners completed an inventory of dementia trainings given to staff, as well as to clients, at all senior centers in Delaware. An informal environmental scan of dementia trainings provided to healthcare providers throughout the state was conducted, as well a compilation a of required dementia lessons available for CNAs in Delaware. This cataloguing was to see what training was currently available and where Delaware's professionals need more training. Because of this, three dementia competency trainings, one a train-the-trainer, were held. The trainings were a collaboration between DSAAPD, the Alzheimer's Association, and the Division of 
Substance Abuse and Mental Health (DSAMH). More multi-professional trainings were developed and conducted throughout the state. The training would be for professionals, inclusive of health care, first responders, retail, and anyone who may deliver a service to someone diagnosed with dementia.

The last goal of the plan sought to improve and expand Delaware Alzheimer's and dementiarelated infrastructure (data, quality assurance, research) by supporting the creation of a Delaware Center for Alzheimer's and Related Dementias (DECARD). ${ }^{11}$ DECARD is a virtual hub of dementia information and resources. As a statewide collaboration, DECARD fosters collective ownership and innovation while working toward improving and expanding Delaware's Alzheimer's and dementia-related infrastructure through data, quality assurance and research. It is a partnership between DSAAPD, the Alzheimer's Association, Delaware State University and University of Delaware. This work also included getting the cognitive impairments module added to the Behavioral Risk Factor Surveillance System (BRFSS) in Delaware. BRFSS is the nation's premier system of health-related telephone surveys that collect state data about U.S. residents regarding their health-related risk behaviors, chronic health conditions, and use of preventive services. ${ }^{12}$ Delaware will use the cognitive module to inform how the state addresses dementia and other cognitive impairments in the future.

On recommendation of partners from the Alzheimer's Plan work, DSAAPD instituted two programs available to those living with dementia and their caregivers. The Nurse Navigator Program utilizes specialized nurses within DSAAPD that support participants diagnosed with dementia and their caregivers by connecting them to services, educating them, and collaborating with health care providers and agencies, all in a person-centered approach. These nurses have been vital team members for families trying to steer the difficult landscape of services and supports for their loved ones. DSAAPD also instituted the Resources Enhancing Alzheimer's Caregiver Health (REACH). Through the Rosalynn Carter Institute for Caregiving (RCI), trained nurses are coaches of the REACH, an evidence-based curriculum. REACH provides education, a focus on safety for the client, support for the caregiver, and skills building to help caregivers manage difficult client behaviors and decrease their own stress. REACH is an in-home, tailored, caregiver support intervention consisting of individual sessions in the home or by telephone. ${ }^{13}$

\section{Success of the Federal Alzheimer's Grant}

In 2014, DSAAPD applied for and received a federal dementia grant. This grant was written to position DSAAPD to accomplish some of the goals of the unfunded Alzheimer's Plan to and fill the gaps in Delaware's dementia-capable system of support. The grant ran from September 1, 2015 to August 31, 2019. Activities included several expanded and new services for people living with ADRD and their caregivers, as well as training opportunities for professionals. Activities included

- Community Living Expansion. Provided transportation and companionship services to individuals diagnosed with Alzheimer's disease or related dementias so that they had access to community resources and opportunities for personal, social, and/or educational enrichment. United Cerebral Palsy administered this program. 
- Legal Services Voucher Program. People diagnosed with Alzheimer's disease or related dementias were provided a voucher to seek legal services from participating attorneys.

- Dementia Competency Training. Professional trainings developed in partnership with the Alzheimer's Association and the American Bar Association. The legal trainings helped prepare members of the Delaware Bar to participate in the legal services voucher program and likely has had a lasting impact on the dementia friendliness of the Delaware Bar.

- Lifespan Respite Expansion. Caregivers of those diagnosed with Alzheimer's disease or related dementias were provided a voucher for respite services. Respite is a temporary break for caregivers from their regular caregiving responsibilities. Easterseals administered this program.

- Savvy Caregiver. A FREE training series for family caregivers of those diagnosed with dementia held at all six of DSAAPD's caregiver resource centers around the state (Wilmington Senior Center, Newark Senior Center, Easterseals New Castle and Georgetown, Modern Maturity Center and CHEER).

- Sensory Technology Pilot Program. This pilot program received a lot of attention from our federal partners, and other states were interested in our outcomes. It focused on home monitoring of people with Alzheimer's disease or related dementia using technology. Sensor Insight, a subsidiary of IBM, administered this program.

Through the grant, DSAAPD was able to provide 36987.45 hours of direct services, including 21,838.20 hours of respite utilized under the Lifespan Respite program by 507 caregivers for those with Alzheimer's disease or related dementias. Service hours totaling 3,114.25 were provided under the Community Living program to 58 individuals with Alzheimer's disease or related dementias, and 192 caregivers participated in Savvy Caregiver over 688 hours. Through the legal services program, 28 hours of legal vouchers were utilized; 11,025 hours of sensory technology services were rendered to seven participants, equaling five hours of active participation a day per participant; 57 legal professionals received 258 hours of legal training; and 69 other professionals received 36 hours of dementia training.

Though the grant is ended, legal services, lifespan respite, and community living have continued through other sources of funding within DSAAPD. In addition, each Caregiver Resources Center has continued to offer Savvy Caregiver classes at their locations.

DSAAPD was able to lay the groundwork for Dementia Friendly Delaware (DFD) with the efforts of this grant and the Alzheimer's Plan. DSAAPD and partners, including Lt. Governor Bethany Hall-Long and the Behavioral Health Consortium, are working together to support people diagnosed with dementia and their caregivers though an innovative new initiative: DFD. DFD provides a system of technical assistance, tools, and resources to assist communities and individuals in taking action to improve community and system capabilities; optimize the health, wellbeing, and involvement of people with dementia and their care partners; and support them to continue in their roles. Delaware joins a network of over fifty communities all over the country to prepare for the personal, social, and budget impacts of dementia by addressing community needs and increasing support for people impacted by dementia. ${ }^{14}$ 
Doi: $10.32481 /$ djph.2021.09.003

\section{Dementia Friendly Delaware}

The Dementia Friendly America (DFA) movement began in September 2015 following the White House Conference on Aging and is based upon Minnesota's statewide successful initiative, ACT on Alzheimer's. DFA launched in 2015 with pilot communities in Denver, CO; Prince George's County, MD; Santa Clara County, CA; Tempe, AZ; and the state of West Virginia. ${ }^{1}$ Delaware launched its effort in 2019.

DFD ensures every part of the community plays a role and can work together to take steps to create a dementia friendly culture. This includes businesses, such as banks and financial and legal services who support customers with dementia, and employers supporting employees who are caregivers. Health care systems can promote early diagnosis and options for ongoing care and support. Communities of faith provide welcoming and engaging environments for those with the disease and their caregivers. Local governments plan and implement housing, transportation, public spaces, and emergency response that enable people with dementia to thrive in the community. Neighbors and community members are understanding and supportive to those around them, including individuals with cognitive impairment. Residential care and communitybased supports offer a range of services to maximize independence and support ongoing community engagement with a variety of options adapted to cognitive decline.

Taking an all-sectors approach is a way to build engagement across many parts of the community. Unique to DFD, sector guides are provided to agencies and organization to provide information, resources, and actions that specific sectors can take, such as environmental tips toward dementia friendliness. In the Business sector guide, tips include providing quiet places to sit and relax, and making sure there are well-lit hallways, uncluttered spaces and prominent, easy-to-understand signs for restrooms and other important places. If the community and system have the capability to adopt dementia friendly practices, everyone in our state will benefit. We also believe that the training provided will have a positive effect on other populations, like those with autism.

While momentum is strong for the DFD to be successful, the Coronavirus upended any progress toward implementation. DSAAPD and its partners are continually working to ensure that the initiative is successful and plans to reestablish efforts in 2022.

\section{Plans for the Future}

\section{Behavioral Health Consortium}

The Delaware Behavioral Health Consortium is a premier consortium comprised of private and public organizations and advocates that work through a shared plan to improve behavioral health system within the State of Delaware. Lieutenant Governor Bethany Hall-Long chairs the Consortium and has a unique passion for this work as she is a public health nurse. Although the Consortium was created to primarily address the opioid epidemic, community outreach was conducted to create the priorities for the consortium. It was through this outreach that it was made clear that there was concern about how the state treats and support those with ADRD and their caregivers. This concern was one of those included in the initial three-year Report, ${ }^{15}$ and was placed within the work plan for the Family and Community Readiness Committee (one of six committees that have taken on the recommendations from the initial report). The Consortium as a whole has achieved the majority of the goals outlined in the initial report, but it continues to 
work on rising issues. The Consortium continues to try to be proactive to the needs of the state and push for innovation. The Family and Community Readiness Committee is uniquely dedicated to the advancement of treatment and support for the Alzheimer's community.

The Family and Community Readiness Committee is comprised of Alzheimer advocates, state agencies such as DSAAPD, and private citizens. The Committee is dedicated to taking on the recommendation of exploring how to better support the aging population and their mental health needs. One of the first steps of the Committee was to conduct a needs assessment for the aging population, which was done through a collaboration with DSAMH. The report is a jumping off point for the Committee to identify priorities and engage stakeholders on them.

\section{Cross Agency Collaboration: DSAMH Aging Well with Behavioral Health Issues in Delaware}

A staple practice across the Consortium and its committees is to bring partners together to collaborate and innovate. This approach was used in addressing their task of creating and conducting geriatric behavioral health or substance use disorder evaluations and needs assessments for treatment. The Committee worked with DSAMH, with help from We in the World, an organization that is known for their equity analysis, to conduct a gap analysis which culminated in a report. They spoke with multiple stakeholders and state agencies to understand what was currently occurring with the aging population, and then created the Aging Well with Behavioral Health Issues in Delaware report which reported on the gaps and consisted of over 20 recommendations.

The DSAMH Aging Recommendations consist of a tiered approach based on risk level, with the lower tiers being deemed for everyone and those with low risk, and the higher tiers being for those who have the highest risk. The main recommendations are:

- Build capacity to identify and improve mental health and addiction outcomes by applying a proactive population health approach and equity lens;

- Expand health care and community capacity for geriatric behavioral health supports to meet and coordinate the needs of the highest risk and medium/rising risk populations;

- Identify and build supports for life transition points that are moments for increased risk; and

- Create conditions to support well-being for all people aged 50+ as they age.

The recommendations take a holistic approach to addressing the concerns. Each recommendation has even more detailed recommendations that outline what specifically could be done, and the Committee is currently working to identify key priorities. DSAAPD has also reviewed the recommendations and is working with DSAMH on them. The Consortium constantly works to increase cross agency collaboration and also build in private investment and ownership to create stability in the solutions that are developed.

\section{Expanding the Bridge Clinics}

Some of the highlights from the recommendations include increasing access to treatment, lowering the age that people are able to receive resources, and to create environments that allow the aging population to continue to thrive. Specifically, there was a recommendation to expand 
the Bridge Clinics to include a geriatric clinic. The Bridge Clinics, which are a DSAMH entities, have been an innovative approach to getting various people into rapid treatment. There are three clinics located in each county that provide rapid assessment and treatment for those with mental health and substance use issues. The Bridge Clinics provide treatment until people can get into more specific treatment. It was recommended that these clinics expand their services to address the needs for geriatric mental health. This would help to lessen the burden that police face when they respond to calls that involve those who have dementia, such as instances when people wander or are disorientated. It would also strengthen the treatment system and move it toward pro-action.

\section{Exploring Policy Recommendations on Provider Education and Support for Caregivers}

Building out the treatment systems includes building out the workforce; this has been front of mind for the Family and Community Readiness Committee. There has been a specific focus on how to improve training for providers so that they can be better informed in how to work with those who have ADRD. In 2009, the Delaware State Legislature passed HB 159. This bill requires the Department of Health and Social Services (DHSS) to adopt regulations that require at least one hour of training annually for certified, licensed, or registered healthcare providers, as well as for healthcare providers who are partially or fully funded by the State, who provide services to persons diagnosed as having Alzheimer's disease or other forms of dementia, or with mental illness. ${ }^{16}$

This work coincides with the work from the State Plan as well as to recommendations from the Aging Well Report around expanding training and competency building for geriatric mental health and addiction across the continuum of care. Training is one step to improving the quality of treatment that those with ADRD receive. The Committee is exploring if legislation is needed to further codify these efforts.

\section{Conclusion}

Ultimately, Delaware has been actively working to address the rising concerns around how to better support the aging populations and more specifically those who have ADRD and their caregivers. The COVID pandemic has specifically highlighted the need to further think about how we better support caregivers and those with ADRD. There has also been a collective movement to holistically address the needs of those with ADRD through initiatives such as Dementia Friendly Delaware. The work that DSAAPD is doing with the implementation of their State Plan is the foundation for programs and support. But this is not a single agency issue and so the inclusion of multiple partners and stakeholders is necessary to ensure that the issue is addressed holistically. This is where the inclusion of the Behavioral Health Consortium is key to assist with engaging other stakeholders and promoting issues and innovation that come from advocates. The Consortium is a tool to increase collaborators which helps to strengthen funding and expand the base of possible clients. Overall. the state of Delaware is working to on innovative solutions to work to better support those with ADRD and their caregivers holistically.

\section{References}

1. Alzheimer's Association. (n.d.) Facts and Figures. Alzheimer's Disease and Dementia. Retrieved from https://www.alz.org/alzheimers-dementia/facts-figures 
Doi: $10.32481 /$ djph.2021.09.003

2. American Psychological Association. (n.d.). Family Caregiving. http://www.apa.org/about/gr/issues/cyf/caregiving-facts.aspx

3. United States. (1978). Older Americans Act of 1965, as amended. Washington, D.C.: Administration on Aging, Office of Human Development Services, U.S. Department of Health, Education, and Welfare.

4. Division of Services for Aging and Adults with Physical Disabilities. (2020, Sep 24). Latest Delaware state plan on aging approved. Retrieved https://dhss.delaware.gov/dhss/dsaapd/stateplan_approval_2020.html

5. Division of Services for Aging and Adults with Physical Disabilities. (2020). 2020 - 2024 Delaware state plan on aging. Retrieved from https://www.dhss.delaware.gov/dhss/dsaapd/files/state_plan_on_aging_20_24.pdf

6. Delaware Department of Health and Social Services. (2014, Feb 18). Delaware releases state plan to address Alzheimer's disease and related disorders. Retrieved from https://www.dhss.delaware.gov/dhss/pressreleases/2014/alzheimersassociationrelease021.html

7. Division of Services for Aging and Adults with Physical Disabilities. (2013, Dec). Delaware State Plan to Address Alzheimer's Disease and Related Disorders. Retrieved from https://www.dhss.delaware.gov/dhss/dsaapd/files/alzheimers_plan.pdf

8. Division of Services for Aging and Adults with Physical Disabilities. (n.d.) Alzheimer's Toolkit. http://dhss.delaware.gov/dhss/dsaapd/alzheimers_toolkit.html

9. Centers for Disease Control and Prevention. (n.d.). Healthy Brain Initiative. https://www.cdc.gov/aging/healthybrain/index.htm

10. Delaware Center for Alzheimer's Disease and Related Dementias. (n.d.). Homepage. https://decard.org/

11. Centers for Disease Control and Prevention. (n.d.). BRFSS. https://www.cdc.gov/brfss/index.html

12. Rosalynn Carter Institute for Caregiving. (n.d.). Dementia. https://www.rosalynncarter.org/programs/dealing-with-dementia/

13. Dementia Friendly America. (n.d.) Homepage. https://www.dfamerica.org/

14. Ciolino, N. (2019, April 30). Delaware seeks to be more "dementia friendly". Delaware Public Media. Retrieved from https://www.delawarepublic.org/post/delaware-seeks-bemore-dementia-friendly

15. Delaware Behavioral Health Consortium. (n.d.). Three-year action plan. Retrieved from https://ltgov.delaware.gov/wpcontent/uploads/sites/27/2018/05/delaware_bhc_threeyearactionplan_2018.pdf

16. Delaware General Assembly. (n.d.). House Bill 159. Retrieved from https://legis.delaware.gov/BillDetail?LegislationId=20168

Copyright (c) 2021 Delaware Academy of Medicine / Delaware Public Health Association. 
This is an Open Access article distributed under the terms of the Creative Commons Attribution Non-Commercial License (https://creativecommons.org/licenses/by-nc-nd/4.0/) which permits unrestricted non-commercial use, distribution, and reproduction in any medium, provided the original work is properly cited. 